\title{
Consolidación, construcción y modelación de un «yo», o la manera como el lenguaje modela una realidad (el caso de las cartas de relación de Hernán Cortés)*
}

Fecha de recepción: 5 de mayo de 2017

Fecha de aprobación: 30 de junio de 2017

\section{Resumen}

En el presente estudio haré un detallado análisis -a través de ejemplos concretos- de la manera como conquistadores y cronistas modelaron su propio «yo», con el objeto último de convencer -a través de dicha modelación- a un receptor real y virtual de que sus propios comportamientos ante los hechos estaban más que justificados. Para ello, cada autor hizo un uso adecuado -dentro de un sistema genérico concreto- de una forma expresiva que correspondiera tanto a sus intereses, como a las exigencias del receptor. Es claro que en el sistema genérico del siglo XVI, dos de estas formas permitían -sin pérdida del decoro- la presencia de un «yo»: la carta de relación, y la relación de sucesos («memorial de guerra»).

Palabras clave: «yo», automodelación, ideología, géneros literarios, intencionalidad.

Citar: Espítia Ortíz, D. L. (enero-junio de 2017). Consolidación, construcción y modelación de un «yo», o la manera como el lenguaje modela una realidad. (El caso de las cartas de relación de Hernán Cortés). La Palabra, (30), 131 - 149. doi: https://doi.org/10.19053/01218530.n30.2017.6960

\section{David Leonardo Espitia Ortiz}

Doctor en Estudios Literarios de la Universidad Autónoma de Barcelona (2016), y Magíster en Literatura de la Universidad Autónoma de Barcelona (2003). Docente de la Universidad Pedagógica y Tecnológica de Colombia.

1spitia@gmail.com

*Artículo de reflexión, producto del trabajo de investigación realizado en el Grupo Senderos del Lenguaje. 


\section{la palabra}

Consolidation, Construction and Fashioning of a «Self», or the Way in which Language Models a given Reality. (The Case of the Letters of Relation of Hernán Cortés.)

\section{Abstract}

The present study uses concrete examples to give a detailed analysis of the way in which conquistadores and cronistas [chroniclers] fashioned their "self", with the objective of convincing a real and virtual receptor that their behaviors regarding the events were justified. For this, each author makes adecuate use of an expressive form -within a concrete genre system- that corresponds both to his own interests and to those of the receptor. It is clear that in the generic system of the XVI centruy, two forms allowed the presence of the «self» without loss of decorum: the letter of relation, and the relación de sucesos [report of events].

Keywords: «Self», Self modelling, Ideology, Literary genre, Intentionality

\section{Consolidation, construction et configuration d'un "je", ou comment le langage façonne une réalité (Le cas des lettres de relation d'Hernán Cortés)}

\section{Résumé}

Nous analyserons à partir d'exemples de quelle manière les conquistadors et chroniqueurs ont construit leur "je", afin de convaincre le récepteur réel et virtuel de la justification de leurs comportements face aux faits. Pour cela, chaque auteur a utilisé une forme expressive -parmi un genre en particulier- conforme á ses propres intérêts et aux exigences du récepteur. Nous considérerons que deux genres au XVIe siècle ont permis -tout en gardant la politesse- la présence d'un "moi» dans la lettre de relation et le rapport de faits ("mémorial de guerre")

Mots-clés: “je”, création du “je”, idéologie, genres littéraires, intention. 
En las cartas de relación escritas por los primeros descubridores y conquistadores -piénsese en Colón y Cortés-, o en las extensas crónicas tanto del descubrimiento como de la conquista del Nuevo Mundo -las crónicas de Indias-, nos encontramos ante relatos escritos en primera persona. Lo curioso es que cuando leemos estos textos epistolares o cronísticos nos surge, de inmediato, una preocupación por el lugar del «yo» a lo largo de la narración: nos preguntamos por la función de ese «yo» en el desarrollo del relato. Y más cuando -como ocurre con un Bernal Díaz del Castillo, un Cabeza de Vaca o un Inca Garcilaso- se puede rastrear una especie de autoconciencia autoral: a cada paso, Bernal Díaz va consolidando una identidad de escritor que opone, muy intencionalmente, a la identidad de un escritor como Francisco López de Gómara, ese cronista que, paradójicamente, le serviría como modelo formal para la elaboración de su propia Historia verdadera de la conquista de la Nueva España.

Pero a pesar de que nos encontramos con un «yo» en estos relatos, no podemos referirnos a ellos como relatos autobiográficos. Silvia Molloy (2001) señala, a este respecto, que a pesar de que los relatos en primera persona abundan durante la colonia, y a pesar de que existe una preocupación del «yo» en estos textos, «su finalidad pri- maria no es autobiográfica, aun cuando la autobiografía constituya uno de sus logros involuntarios» (p. 13). Más aún, «las circunstancias en que se escribieron esos textos excluyen, o al menos modifican considerablemente, la autoconfrontación textual -"yo soy el tema de mi libro" [recordemos a un Montaigne]- que caracteriza la escritura autobiográfica» (p. 13). Incluso, señala Molloy,

el hecho de que los textos mencionados se destinaran, ante todo, a un lector privilegiado (el rey de España, el obispo de Puebla, el tribunal eclesiástico) que ejercía poder sobre el escritor y su texto; el hecho de que la autonarración fuera menos un propósito que un medio para lograr ese propósito; $\mathrm{y}$, por último, el hecho de que rara vez haya crisis en esta escritura del yo (o rara vez haya un yo en crisis), hacen que el resultado sea sólo tangencialmente autobiográfico. (p. 13).

En efecto, es tangencialmente autobiográfico, y lo es -junto con lo señalado por Molloy- por una razón esencialmente historiográfica. En cada momento de la historia de la literatura, en cada período literario, los escritores tienen a disposición un sistema de géneros sobre los cuales pueden elegir, dependiendo siempre de sus propios intereses y de su propia formación. Como nos lo señala Claudio Guillén (1998), los sistemas de géneros «han sido la zona de combate in illo tempore, el lugar de selección, aprendizaje, rechazo o encuentro entre el escritor y los paradigmas -encarnados en conceptos y sobre todo en obras y autores superiores y normativos- rectores de un período histórico singular» (p. 205).

En muchos casos, la elección de un género se hace de manera consciente y responde a propósitos concretos; en otros, en cambio, simplemente es el resultado de una imitación necesaria. ¿Qué ocurría, en este sentido, con el sistema de géneros del siglo XVI, aquel sistema con el que contaban conquistadores como Colón y Cortés, o cronistas como Bernal Díaz del Castillo o Francisco López de Gómara? ¿A qué intereses respondían cuando, dentro de las posibilidades genéricas de las que disponían, elegían formaciones textuales no ficcionales como las cartas de relación, las relaciones de sucesos de guerra o, incluso, como bien lo señala Alburquerque García, relatos de viajes? Alburquerque describe, a este respecto, un conjunto de rasgos formales que comparten las cartas de relación y los relatos de viajes: en ambos casos nos encontramos con textos factuales $\mathrm{y}$, además de ello, nos encontramos con una especificidad genérica común, 
esto es, su dimensión testimonial. Lo interesante es que esta dimensión -como lo indicaré a continuación- no era indecorosa, ya que era la manera como el autor garantizaba -a través del testimonio-que lo dicho era efectivamente cierto (existe una estrecha relación entre lo testimonial y la veracidad del relato). ${ }^{1}$

Por otra parte, la profesora González Otero (2016) señala, igualmente, que los relatos de viajes se pueden nutrir de elementos de la autobiografía, la epistolografía, la etnografía e, incluso, de la historia misma (p. 70). Para González Otero, los primeros relatos de viajes escritos en Latinoamérica son las cartas del descubrimiento de Cristóbal Colón, en las que se muestra por primera vez «el reconocimiento de un mundo más amplio y extenso» (p. 73).

Indicado esto, ¿había alguna diferencia en el hecho de que Gómara fuera humanista y respondiera a una exigencia de su rey, mientras que Bernal Díaz fuera un soldado-cronista y respondiera a necesidades particulares y beneficios futuros? Es claro que, en términos pragmáticos, tanto la intención autoral como el género escogido por estos relatores respondían a una especie de práctica periodística a través de la cual se informaba a la Corona sobre los sucesos que acaecían en el Nuevo Mundo. En últimas, ante la necesidad de informar, no podían sino elegir este tipo de géneros no ficcionales.

Pero lo particular e interesante de esta cuestión es que el tipo de información que introducían, y el género al que tuvieron que acudir estos descubridores $\mathrm{y}$ conquistadores, estaba ligado a la presencia de un «yo» y de un «tú». A este respecto, es claro que en el siglo XVI introducir el «yo» en un género como la carta, no era indecoroso. Entre otros motivos, porque el lenguaje utilizado pertenecía a un nivel estilístico «un grado por debajo de lo que correspondía en cualquier otro cause expresivo»; «lo que es alto en una epístola -como indica el profesor Gonzalo Pontón- equivale a lo mediocre en otras formas discursivas, y lo mediocre a lo bajo. En el caso de la epístola familiar, y dado que el estilo que le corresponde es el ínfimo, este se halla a un nivel aun inferior, y por lo tanto nuevo, sin equivalente en otras manifestaciones literarias» (Pontón, 2002, p. 190). El lenguaje de una carta era humilde, convencional, familiar, cuestión que le permitía, justamente, acercar al emisor con su receptor, colocando así a ambos sujetos en un mismo lugar. De aquí que, la carta sea una especie de diálogo interrumpido, esa quaestio que se establecía con la esperanza de una respuesta, en muchos casos, nunca dada.

Introducir el «yo» en otros géneros era, en cambio, poco decoroso. Recordemos, brevemente, que según la retórica clásica, utilizar el «yo» para hablar sobre uno mismo no era una cuestión bien vista. El mismísimo Emperador, Carlos $\mathrm{V}$, en 1552 -como nos lo recuerda Francisco Rico-, «consideraba poco prudente y suspecto de "vanidad", de pecaminoso "apetito de gloria", que una "persona" quisiera dar "entera noticia" de sí ... La retórica desaconsejaba hablar de uno mismo, ni en bien ni en mal, salvo si se trataba de hacer notorio a la posteridad cómo una "nobilis virtus" había llegado a triunfar sobre el "vitium"» (Rico, 2010, p. 66, nota 34). Perfecto ejemplo de ello son las Confesiones de San Agustín, o el hecho de que Ignacio de Loyola, para hablar sobre su vida, prefiriera que sus memorias fueran redactadas por mano ajena.

Lo que ocurría, además, con aquellas formas expresivas antes señaladas (las cartas de relación y los memoriales de guerra), es que la aparición del «yo» estaba necesariamente mediada por las alegaciones de servicios o relaciones de hechos de guerra que, sin duda, la Corona misma comenzaría a exigir.

Véase, a este respecto, Alburquerque (2008, p. 14). 
Las primeras cartas de Colón, por ejemplo, se van modificando una a una ante las constantes exigencias de los Reyes Católicos. A medida que avanzan los descubrimientos y que se volvía más compleja la administración de los lugares conquistados, cada vez son más precisos los intereses de la Corona y, por ello, las exigencias en el control de la información. Entre la primera carta de Colón y la cuarta, se puede rastrear un cambio significativo que responde a la misma conciencia por parte de los Reyes de lo que estaba ocurriendo. Cada vez necesitaban más información, y esta tenía que ser más precisa. Tanto es así, que todo este conjunto de cartas iniciales, las de Colón y las de Cortés, serán remplazadas en un futuro por las denominadas cartas geográficas de Indias, que al final no eran otra cosa que un conjunto de respuestas a un cuestionario establecido por la Corona. Lo que significa todo esto es que, en efecto, la carta estaba condicionada y mediada por intereses externos, y es por ello que en la Segunda carta de relación de Hernán Cortés existía una restricción en tanto que en ella -siguiendo a Walter Mignolono se transcribe «la observación "libre" de quien escribe, de lo que ve quien escribe, sino que responde, de alguna manera, a los pedidos oficiales» (Mignolo, 1992, p. 71).

Pero independientemente de estas exigencias oficiales, la presencia del «yo» en estas cartas de relación y en estos memoriales de guerra, no era una cuestión baladí. En el presente trabajo quiero presentar la manera como el «yo» de la Segunda carta de relación escrita por Hernán Cortés se va consolidando, construyendo, modelando; y al hacerlo, va dejando rastros de una serie de cuestiones ideológicas e intencionales que es absolutamente necesario presentar. Como se verá en el presente estudio, esa consolidación, construcción $\mathrm{y}$ modelación del «yo» depende de diversos factores. En primer lugar, de las exigencias oficiales, pues es claro que Cortés estaba escribiendo su carta de relación a Carlos V, y que al ser una carta que funcionaba como un documento legal, todo lo que se afirmaba en ella era una declaración jurada que, por tanto, podía ser usada en pleitos y causas judiciales, como de hecho ocurrió a lo largo del juicio de residencia hecho a Cortés.

En segundo lugar, del estilo de las cartas de relación, ya que como buen notario que era, Cortés sabía que un buen informe exigía un tono desapasionado para ser creíble, de aquí que percibamos un tono ecuánime, distante y moderado en su narración, sin olvidar su carácter familiar. $\mathrm{Y}$ en tercer lugar -como consecuencia de los otros dos factores-, de la elección necesaria de una forma expresiva no ficcional utilizada para informar, como ocurre con las cartas de relación o los memoriales de guerra. Solo teniendo en cuenta estos elementos, es posible definir el lugar de un «yo», y por ello, es claro que cuando Cortés estaba construyendo su propia imagen ante su último destinatario, lo hacía sin una real autonomía, pues dependía necesariamente de aquellas circunstancias externas señaladas, que en últimas son contextuales, históricas.

Señalado lo anterior, hay que indicar que las cinco cartas de relación escritas por Hernán Cortés se redactaron entre 1519 y 1526. La primera de ellas, tal vez la que más objeto de estudio ha generado, se conoce también con el nombre de Carta de Veracruz, y a diferencia de las otras cuatro, está firmada por los miembros del Cabildo y Regimiento de la Villa Rica de la Vera Cruz con fecha de 20 de julio de 1519. Y digo que esta relación es sobre la que más se ha investigado porque fue una de las últimas en conocerse y la 
única sobre la que su autoría aún está en discusión. ${ }^{2}$ Justamente la búsqueda de esta relación llevó al historiador escocés, William Robertson, a descubrir en el siglo XIX el Códice de Viena (Codex Vindobonnensis), la única copia manuscrita de la época que contiene las cinco relaciones. ${ }^{3}$ Cabe señalar que en este Códice, al igual que en el Códice de Madrid — también del siglo XVI, en el que aparecen los manuscritos de cuatro de las relaciones, pues no está la carta de Veracruz-, se encuentran los largos títulos que preceden a la Segunda y Tercera relaciones impresas en Sevilla en 1522 y 1523 , respectivamente. ${ }^{4} \mathrm{La}$ hipótesis sugerida por Delgado Gómez sobre la procedencia de estos extensos títulos, es que a pesar de que no se puede establecer un stemma que nos permita filiar estas ediciones impresas con las manuscritas, «hay un hecho extraño» que nos puede llevar a ello:

Concretamente el hecho de que los dos largos títulos, típicos de la edición impresa de la época, que preceden a las relaciones Segunda y Tercera apare- cen también en los manuscritos. No hay duda de que el autor de ambos títulos es el editor Cromberger, ya que las otras relaciones carecen de él. La presencia de esos títulos en los códices de Viena y Madrid podría hacer pensar que ambos códices se sirvieron también de los textos de Cromberger, pero esa hipótesis no puede mantenerse a la vista de las variantes que consignamos en esta edición. Lo que sí es seguro, sin embargo, es que los compiladores de ambos códices conocían la existencia de las ediciones impresas de Cromberger [...] (1993, p. 72).

Así que para el caso de la Segunda relación -que es la que ahora interesa-, contamos con una primera edición hecha en Sevilla en 1522 por el editor Cromberger, que fue conocida por los compiladores de los códices antes señalados. Ahora bien, esta relación fue escrita dos años antes y su redacción se ajusta, como bien lo plantea Delgado Gómez,
[...] al modelo de Cortés, quien espera para redactarla hasta haberse repuesto lo suficiente de la desastrosa retirada en la que ha perdido la mitad de sus hombres, cuando la alianza con sus aliados tlaxcaltecas se ha consolidado lo suficiente como para que estén ya formulados claramente sus planes de reconquista de Tenochtitlán (1993, pp. 48-49).

Por supuesto, antes de la recuperación de Tenochtitlán -relatada en la Tercera relación-, Cortés funda Segura de la Frontera, una ciudad desde la que dirigirá la reconquista. Puesto que es en esta ciudad donde consolida su alianza con los tlaxcaltecas $\mathrm{y}$, alejado ya de la derrota sufrida tras la «Noche Triste», escribe su Segunda carta de relación. El final del relato de Cortés aclara el lugar y la fecha en la que se escribió:

Muy Alto y Muy Excelentísimo Príncipe: Dios nuestro Señor la vida y muy real persona y muy poderoso estado de Vuestra Sacra Majestad con-

2 Frankl [1962] y posteriormente Delgado Gómez [1993] han argumentado que la redacción de la carta de Veracruz fue realizada por Cortés.

3 Una descripción detallada de la «peregrinación» de este Códice, se encuentra en la excelente edición crítica que preparó Ángel Delgado Gómez de las Cartas de relación para la Editorial Castalia, publicada en 1993. Véanse allí las páginas 64 - 68.

4 Por supuesto, el extenso título que acompaña la Segunda relación es una descripción de los principales objetivos que tiene Cortés al escribir sus cartas: en primer lugar, el sometimiento a la Corona de los descubrimientos que ha hecho en el Yucatán; y, en segundo lugar, la conquista de «una grandísima provincia muy rica llamada Culúa en la cual hay muy grandes ciudades y de maravillosos edificios y de grandes tratos y riquezas entre las cuales hay una más maravillosa y rica que todas llamada Temustitán que está por maravillosa arte edificada sobre una grande laguna, de la cual ciudad y provincia es rey un grandísimo señor llamado Muteeçuma, donde le acaecieron al capitán y a los españoles espantosas cosas de oír» (Cortés, 1993, pp. 159-160]. 
serve y aumente por muy largos tiempos con acrecentamiento de muy mayores reinos y señoríos como su real corazón desea. - De la Villa Segura de la Frontera desta Nueva España, a 30 de octobre de 1520 años. (1993, p. 309).

\section{$* * *$}

Una de las cuestiones centrales que se discute en esta Segunda carta de relación, es el enfrentamiento legal que existe entre Hernán Cortés y Diego Velázquez, y el escenario en el que se desarrolla dicho enfrentamiento parece claro: por un lado, Velázquez no estaba dispuesto a perder ni uno solo de sus privilegios, y mucho menos la posibilidad de obtener un «rescate» de aquellas tierras que -como previamente se había enterado tanto por Francisco Hernández de Córdoba, como por Grijalba- conformaban un gran botín. ${ }^{5}$ Por otro lado, Cortés tenía la intención de redactar una carta de relación en la que a través de un marco legal legitimara su posición dentro de una jerarquía en la que, en principio, él no podía conquistar y poblar. Finalmente, la legalidad que intenta exponer en su relato puede estar ligada a una cuestión esencial que dominará igualmente toda la narración: me refiero al providencialismo que se per- cibe tanto en el conjunto de la relación, como en ciertos momentos concretos, sobre todo en aquellos en los que Cortés toma decisiones fundamentales que afectan al desarrollo de los acontecimientos.

Uno de estos momentos es justamente el de la captura de Narváez. En este episodio, Cortés establece una relación directa -a manera de justificaciónentre los hechos, tal cual son narrados, y la intervención de Dios en el desarrollo de estos. El recurso retórico que utiliza Cortés para introducir esta «justificación»-esta relación entre Dios y los hechos- y crear a través de ella un efecto en el receptor real-Carlos $\mathrm{V}-$, consiste en la construcción de una clara contraposición ideológica entre la figura del propio Cortés y la figura de su principal oponente, Diego Velázquez. Lo reseñable, a este respecto, es que esta contraposición ya se encontraba como rasgo distintivo en la Carta de Veracruz, la hoy llamada Primera carta de relación, ya que en esta se enfrentaban dos posiciones ideológicas distintas, dos tipos históricos de actitudes humanas y políticas: por una parte, se encontraba la liderada por Diego Velázquez, definida a grandes rasgos como un «egoísmo comercial de miras estrechas y la limitación conforme a este de las empre- sas descubridoras a mero rescate en forma de un comercio costero»; y, por la otra, la de Hernán Cortés, caracterizada como «el principio del interés de Dios y del Rey ... que quebranta toda disposición opuesta a este principio» (Frank1, 1962, p. 27). Acotando aún más esta contraposición, y siguiendo la exposición dada por Víctor Frankl [1962], Velázquez representaba el particularismo de la conquista, esto es, el interés singular por adquirir riquezas en beneficio propio, mientras que Cortés orientaba su interés hacia el beneficio de lo público, de la Corona, del Rey.

Si miramos desde esta perspectiva la captura de Narváez, el escenario que hemos tratado de describir adquiere todo su sentido. Durante esta captura, Cortés considera que el gobernador Velázquez se ha encargado de convencer a todos sus soldados de que el conquistador de México [Cortés] no era sino un hombre que se había adueñado de la tierra y que se había comportado como un traidor a la Corona, y que, por tanto, era una obligación para con el Rey combatir contra él. El recurso al que acude Cortés para responder ante esta acusación no puede ser otro: es la providencia la encargada de mostrar a todos estos soldados la verdad de los acontecimientos, deján-

$5 \quad$ Previamente a la instrucción fechada el 23 de octubre de 1518 en la que se autorizaba a Hernán Cortés la exploración de Yucatán, Diego Velázquez había enviado, en efecto, dos exploraciones previas: la de Francisco Hernández de Córdoba, fechada en 1517; y la de Juan de Grijalba, fechada en 1518. 
doles ver «la mala intención y dañada voluntad del dicho Diego Velázquez y del dicho Narváez y cómo se habían movido con mal propósito» (Cortés, 1993, p. 265). De este modo, la conclusión del episodio no puede ser distinta: un discurso dirigido al Rey justificando la excelente decisión que ha tomado el propio Cortés, una decisión que en caso de no haber sido tomada tal cual él mismo la describe, las consecuencias hubieran sido perjudiciales tanto para el Rey como para la Corona:

Porque certifico a Vuestra Majestad que si Dios mistiriosamente esto no proveyera y la vitoria fuera del dicho Narváez fuera el mayor daño que de mucho tiempo acá en españoles tantos por tantos se ha hecho, porque él ejecutara el propósito que traía y lo que por Diego Velázquez le era mandado, que era ahorcarme a mí y a muchos de los de mi compañía porque no hobiese quien del fecho diese razón ( 1993, p. 265).

Parafraseando, si Dios no hubiera permitido que aquellos soldados descubrieran la verdad, esto es, la «dañada voluntad de
Diego Velázquez», sin duda, su secuaz Narváez no solo hubiera ahorcado a Cortés, sino también a todos aquellos que conformaban su compañía, impidiéndoles, con ello, informar al Rey de los acontecimientos que, sin duda, lo hubieran perjudicado.

$$
* * *
$$

El escenario de la captura de Narváez se define, como he sugerido, por una contraposición entre dos actitudes humanas distintas, por dos formas de confrontar la realidad. Estas dos actitudes, sin embargo, responden, también, a una construcción retórica -Frankl se refiere a ellas como construcciones «ideológicas» o «míticas»-, ${ }^{6}$ con la cual Cortés intenta legitimar su posición dentro de una jerarquía administrativa. Lo interesante es que esta posición construida por el propio Cortés se va transformando a través del desarrollo textual de la propia carta de relación: si bien en los primeros episodios de la misma, el destinatario real y virtual percibe a un Cortés explorador recorriendo las distintas ciudades entre la costa y Tenochtitlán, tratando, durante este recorrido, de poblar dichas ciudades y de convencer a los indígenas para que comiencen a ser vasallos de
Su Majestad, luego, cuando el conquistador ya se encuentra en la gran ciudad y ha capturado a Moctezuma y se ha enterado de la llegada de Narváez como representante de Velázquez, luego de todo ello, entonces, estos destinatarios ven a otro Cortés, ven a un Cortés dispuesto a defender ese lugar ganado durante el largo y complejo recorrido en busca de Tenochtitlán; con otras palabras, ven a un Cortés que no quiere perder ninguno de los logros conseguidos, que no quiere perder el control y el poder que ha ganado durante dicho recorrido. Es como si cada acontecimiento, como si cada enfrentamiento que tiene con los indígenas o con los propios españoles, fueran ocasiones para modificar la idea que de sí mismo tiene Cortés; es como si en cada paso que da, Cortés estuviera automodelando -utilizando el término de Greenblatt [self-fashioning]- ese «yo» con el que estructura su relato. Por supuesto, dicha automodelación necesariamente está determinada por el fin último de la relación, esto es, la legitimación ante el Rey de la captura de Moctezuma y de la conquista de Tenochtitlán (recuérdense los apartados de Cromberger antes señalados): «y que confiando en la grandeza de Dios y con esfuerzo del real nombre de

\footnotetext{
$6 \quad$ A manera de conclusión de su ensayo, afirma Frankl: «Y por la misma razón ideológica, por ser Cortés esencialmente hombre "político", hombre de "Estado", servidor de la "Corona", lleva en su alma un odio feroz contra el hombre de "intereses particulares", contra el comerciante egoísta, adquiriendo todo su pensar, toda su actividad literaria e histórico-descriptiva y política una faz dualista, un empuje apasionado contra este tipo, contraste encarnado en Diego Velázquez. Por cierto: todo esto es "ideología", es "mito", tanto la grandiosa visión del "reino" y del "servidor absoluto a la Corona" como su contraste, la imagen del "tirano" codicioso y avaro, tanto la auto interpretación de Cortés como la acusación de Velázquez» (Frankl, 1962, p. 73).
} 
Vuestra Alteza -afirma Cortés-, pensaba irle a ver [a Moctezuma] a doquiera que estuviese» (Cortés, 1993, p. 162).

Así que el «yo» que se enfrenta a Narváez y cuyo encuentro producirá su primera derrota -la «Noche Triste»-, no es el mismo que percibimos al comienzo de la relación -ese «yo» que deja Cempoal en busca de la gran ciudad-, ya que, en medio de ambos momentos, el lector puede percibir progresivamente cómo el conquistador va adquiriendo poder, y, a través de él, una autolegitimación de cada uno de sus actos. Lo más relevante de este asunto es que el «yo» que se va modificando a lo largo de la relación se comporta $y$, a su vez, se define, como una figura sometida a una autoridad superior, en nuestro caso, al Rey, y, con él, una vez más, a Dios.

Recordemos, a este respecto, que en Renaissance Self-Fashioning, Stephen Greenblatt aclara durante su estudio -dedicado a seis autores, More, Spenser, Marlowe, Shakespeare, Tyndale y Wyatt- que hay un conjunto de condiciones propicias para las prácticas de la automodelación [«set of governing conditions common to most instances of self-fashioning»]. Una de estas condiciones puede servirnos, justamente, como modelo para la descripción que estoy proponiendo de ese «yo» que Cortés va transformando.
Greenblatt la sintetiza de esta manera: «Self-fashioning for such figures [como la de Cortés, en nuestro caso] involves submission to an absolute power or authority situated at least partially outside the self -God, a sacred book, an institution such as church, court, colonial or military administration» (Greenblatt, 2005, p. 9).

Desde esta perspectiva, el «yo» que domina este relato se puede definir en su relación con una autoridad que, a su vez, es el destinatario. Recordemos que estamos ante una carta, y que el receptor al que está dirigida es el que delimita el margen y el sentido del relato. Recordemos también que nos encontramos ante la narración de la conquista de una región y ante el interés del autor por legitimar cada acontecimiento durante el proceso de dicha conquista. Ahora, lo que quisiera dejar claro, a este respecto, es que el contenido de ese «yo» no tiene nada que ver con la exhibición de una interioridad particular. No estamos ante lo que Stephanie Merrim ha denominado "spiritual autobiography», en tanto que en esta relación no se manifiesta una revelación de la interioridad del autor. Estamos, mejor, ante lo que la misma autora ha denominado «autobiography/history», esto es, ante la reducción del «yo» a la crónica externa y pública de eventos significativos que justamente ese «yo» ha experi- mentado (Merrim, 1986, p. 60). De este modo, a lo largo de la Segunda carta de relación, se pueden ver ejemplos extraordinarios de la capacidad que tiene Cortés para seleccionar la versión de los acontecimientos que más le competen en función de ese «уо» que quiere mostrar a su destinatario, un «yo» que, además, está sujeto a las reglas de la crónica histórica.

Tomemos un par de ejemplos que así lo ilustren. El primero de ellos lo encontramos al comienzo de la relación, justamente cuando Cortés tiene su primer enfrentamiento con algunos españoles que no estaban de acuerdo con las decisiones que estaba tomando. Estos españoles, «criados y amigos de Diego Velázquez», se querían «alzar» y abandonar la travesía que hasta ahora se iniciaba, la de penetrar en el interior de México, en lugar, como se esperaba, de solo bordear su costa. Eran cuatro españoles, llamados Juan Escudero, Diego Cermeño, Gonzalo de Ungría y Alonso Peñate, los cuales,

según lo que confesaron espontáneamente, tenían determinado de tomar un bergantín que estaba en el puerto con cierto pan y tocinos y matar al maestre dél e irse a la isla Fernandina a hacer saber a Diego Velázquez cómo yo inviaba la nao que a Vuestra Alteza invié y lo que en 
ella iba y el camino que la dicha nao había de llevar para que el dicho Diego Velázquez pusiese navíos en guarda para que la tomasen. (Cortés, 1993, p. 164).

También confesaron -continúa Cortés- que había otras personas que tenían el mismo propósito de avisar a Diego Velázquez sobre aquella nao. Ante tal comportamiento de los españoles, el conquistador no tuvo otra opción que castigarlos «conforme a justicia y a lo que segund el tiempo me paresció que había necesidad y al servicio de Vuestra Alteza cumplía»; y para evitar cualquier otro intento de sedición o motín, y de abandono de la región, cosa que lo dejaría solo en su travesía, «por donde se estorbara el gran servicio que a Dios y a Vuestra Alteza en esta tierra se ha hecho», decidió encallar los navíos, «por donde todos perdieron la esperanza de salir de la tierra y yo hice mi camino más seguro $\mathrm{y}$ sin sospecha que, vueltas las espaldas, no había de faltarme la gente que yo en la villa había de dejar»(Cortés, 1993, p. 164). Lo sorprendente de este relato es que Cortés no hace ninguna referencia al castigo que aplicó a aquellos cuatro españoles, porque, entre otras cosas, no quería dejar saber a su receptor, Carlos V, que desde el mismo comienzo de su expedición ya había españoles que se oponían a sus planes. Si comparamos la información dada aquí por Cortés con la que nos ofrece Bernal Díaz del Castillo, la diferencia es abismal. En el capítulo 57 de la Historia verdadera de la conquista de la Nueva España, se indica el alzamiento de estos cuatro españoles, acompañados en este caso por un vecino de Chiapa llamado Bernaldino de Coria, y por un clérigo, Juan Díaz. ${ }^{7}$ Pues es justamente dicho vecino el que informa a Cortés del intento de estos hombres por abandonar la región, entre otras razones porque el conquistador no había cumplido su promesa de permitirles abandonar, con anterioridad, Cuba, y también porque no les había dado parte del oro enviado a Castilla. Por supuesto, al enterarse de lo que estaba ocurriendo, Cortés

les tomó sus confisiones, y confesaron la verdad y condenaron a otros que estaban con nosotros, que se disimuló por el tiempo, que no permitía otra cosa. Y por sentencia que dio, mandó ahorcar al Pedro Escudero e a Juan Cermeño, y cortar los pies al ---- y al piloto Gonzalo de Umbría y azotar a los marineros Peñates, a cada uno doscientos azotes; $y$ al padre Juan Díaz, si no fuera de misa también le castigaran, mas metiole harto temor. (Díaz del Castillo, 2011, p. 202). ${ }^{8}$

El segundo ejemplo transcurre durante el episodio en el que Cortés hace prisionero a Moctezuma, uno de los episodios más dramáticos del relato. Los antecedentes de la captura parecen claros: Cortés recibe una carta de un capitán suyo que antes había dejado en la villa de la Vera Cruz, en la que le hace una breve relación de las razones por las que ha decidido quemar y destruir la ciudad de Almería. En esta carta, el capitán cuenta allí que Cualpopoca, señor de Nauhtla -ciudad a la que los españoles llaman Almería- intenta matar a cuatro españoles que había pedido como garantía para poder ir a Vera Cruz a rendir honores a Su Majestad, ya que para llegar a dicha ciudad tenía que pasar por tierras de sus enemigos - estos hombres servían como protección para cualquier posible ataque-. Dos de esos españoles escapan, y los otros dos son asesinados. Como represalia a estos asesinatos, el capitán se dirige a Almería «con cincuenta españoles

$7 \quad$ Bernal Díaz señala que estos españoles eran Pedro Escudero, Juan Cermeño, Gonzalo de Umbría, Bernardino de Coria, «los hombres de la mar que se decían Peñates», y el padre Juan Díaz. Como se ve, no hay una concordancia de nombres entre ambas relaciones.

8 Los guiones indican un espacio en blanco tanto en la edición citada, como en el testimonio $G$, esto es, el manuscrito conocido como Guatemala. Véase, a este respecto, Guillermo Serés (2011, pp. 1214-1242). 
y los dos de caballo y dos tiros de pólvora y con hasta ocho o diez mill indios de los amigos nuestros» (Cortés, 1993, p. 213), a destruir Almería. Por desgracia para él y para Cortés, «Qualpopoca, señor de la dicha cibdad, con otros señores sus aliados que en su favor habían venido allí se habían escapado huyendo» (Cortés, 1993, p. 213). Pues, esta carta escrita por aquél capitán acerca de lo ocurrido en Almería, ${ }^{9}$ es la que motiva a Cortés a desconfiar hasta tal grado de Moctezuma, que decide hacerlo prisionero dentro de su propia ciudad:

Y porque en su prisión no hobiese algúnd escándalo ni alboroto, pensando todas las formas y maneras que para lo hacer sin éste debía tener, me acordé de lo que el capitán que en la Vera Cruz había dejado me había escripto cerca de lo que había acaescido en al cibdad de Almería, segúnd que en el capítulo antes déste he dicho, $\mathrm{y}$ cómo se había sabido que todo lo allí suscedido ha- bía sido por mandado del dicho Muteeçuma. (Cortés, 1993, p. 213).

Siguiendo la narración cortesiana, veremos que antes de visitar a Moctezuma en el lugar en que lo había hecho prisionero, esto es, en la misma casa de Moctezuma -astucia de Cortés, como veremos-, decide recorrer la ciudad para comprobar que todo está en orden. Una vez hecho esto, vuelve a casa del emperador para conversar muy amablemente con él y preguntarle si fue en efecto él quien ordenó a Qualpopoca asesinar a aquellos españoles. Moctezuma, a continuación, decide enviar a algunos de los «suyos» a capturar a Qualpopoca para traerlo ante Cortés. Una vez estos han partido en su búsqueda, el conquistador le aclara a su cautivo que necesariamente lo tiene que dejar prisionero hasta que se sepa la verdad sobre lo ocurrido realmente en Almería, y se demuestre, con ello, que él no tiene ninguna responsabilidad sobre los hechos, y que le «rogaba mucho que no rescibiese pena dello porque él no había de estar como preso sino en toda su libertad, y que en su servicio ni en el mando de su señorío yo no le pornía ningúnd impedimento». «Y cerca desto», concluye diciendo Cortés,

pasamos muchas pláticas y razones que serían largas para las escribir y aun para dar cuenta dellas a Vuestra Alteza algo prolijas y también no sustanciales para el caso, y por tanto no diré más de que finalmente él dijo que le placía de se ir conmigo y mandó luego ir a adreszar el aposentamiento donde el quiso estar, el cual fue muy presto y muy bien adreszado. (Cortés, 1993, p. 216).

Es claro que, en este punto, el lector de la relación - sea este el real o el virtual- tiene que cuestionar si tras estas resumidas palabras Cortés está dejando de lado parte fundamental de la exposición; es decir, cabe preguntar por qué esas «pláticas y razones» no fueron, a ojos de Cortés, sustanciales, y,

$9 \quad$ La versión que incluye Francisco Cervantes de Salazar en su Crónica de la Nueva España es casi una copia de la que aquí introduce Cortés. En ella aclara, sin embargo, que el autor [el capitán] pudo ser Francisco Álvarez Chico, o Pedro Dircio. Lo significativo es que la carta está introducida en estilo indirecto, cuando en realidad parece ser una adaptación de la relación de Cortés. Compárese lo antes citado con el final de la carta que introduce Cervantes de Salazar: «“... Los indios amigos eran tan grandes enemigos dellos que al que podían coger no le daban vida. Qualpopoca y otros señores, sus aliados, que en su favor habían venido, se escaparon huyendo, y de algunos prisioneros que tomé, me informé cúyos vasallos eran los que en defensa de la ciudad estaban, los cuales dixeron que de Motezuma, el cual había inviado a mandar a Qualpopoca y a los otros señores que allí habían venido, como a sus vasallos y mascegoales, que sobre seguro matase a los españoles, y que salido vuestra Merced [Cortés] de la Veracruz, viniesen sobre los indios que se habían aliado y ofrescido al servicio del Emperador, y que tuviesen todas las formas que ser pudiesen para matar los españoles que vuestra Merced aquí dexó, porque no se pudiesen ayudar ni favorescer a los rebeldes. Vuestra Merced verá sobre esto lo que conviene hacer, y mire que, pues esto ha prescedido, que no puede estar en esa ciudad, donde es Rey e señor Motezuma, seguro"» (Véase Cervantes de Salazar, 1971, lib. IV, cap. 26). 
sobre todo, si tras esas «pláticas y razones» se estaba ocultando la tensa situación que con seguridad existió en el momento en que Moctezuma tuvo que permanecer recluido ante las miradas y advertencias de Cortés y los suyos. Como indica Delgado Gómez, en este fragmento hay un "constante control sobre la confección y el contenido del discurso» (Delgado Gómez, 1993 , p. 216, nota 212) utilizado por el conquistador.

Si comparamos estas supresiones realizadas por Cortés con la secuencia descrita por Bernal Díaz, vamos a comprobar, una vez más, que el conquistador está seleccionando la información que va a enviar a Carlos V. En el capítulo XCV de la Historia verdadera de la conquista de la Nueva España, se incluye lo que ha dejado de lado Cortés, esto es, el diálogo que se establece entre él y Moctezuma y que, como hemos visto, ha denominado «pláticas y razones». Lo interesante de este diálogo es que ya no solo escuchamos la voz del conquistador, sino también la del emperador mexicano, y es a través de esta nueva voz que percibimos cómo, en efecto, dicho emperador está inquieto por la posición que ha tenido que adoptar respecto a sus «principales», sean estos caciques o sacerdotes, una vez ha sido hecho prisionero. Aquí está en juego, sin duda, su posición en una determinada jerarquía. En el episodio, Bernal
Díaz se refiere, en primer lugar, a los reclamos que hace Cortés a Moctezuma, diciéndole que a pesar de que todo el tiempo está afirmando que es amigo de los españoles y que está al servicio de Su Majestad, en realidad ha enviado a sus soldados a tomar las armas contra los españoles y ha tenido el atrevimiento, además, «de robar los pueblos que están en guarda y mamparo de nuestro rey y señor» (Díaz del Castillo, 2011, p. 349); con otras palabras, Cortés reclama a Moctezuma que, siendo su amigo, lo esté traicionado, y más cuando el comportamiento de Cortés es descrito como ejemplar: «Que, teniéndole por tan su amigo, mandé mis capitanes que, en todo lo que posible fuese, os sirviesen y favoresciesen, y vuestra merced, por el contrario, no lo ha hecho» (Díaz del Castillo, 2011, p. 350). Recordemos que el propósito último del conquistador es evitar a toda costa que, bajo la autoridad de Moctezuma, los mexicanos ataquen y expulsen a los españoles de Tenochtitlán y, para ello, tiene que intentar mantenerlo a su resguardo.

La respuesta de Moctezuma a estos reclamos -en la versión que da de los hechos Bernal Díaz en su Historia verdaderaestá mediada por la intervención previa de Marina, la Malinche, intérprete y amante de Cortés, quien habiendo escuchado el reclamo de Cortés, se dirige al emperador mexicano con las si- guientes palabras: «Señor Montezuma, lo que yo os aconsejo es que vais ['vayáis'] luego con ellos a su aposento sin ruido ninguno, que yo sé que os harán mucha honra, como gran señor que sois, y de otra manera, aquí quedaréis muerto, y en su aposento se sabrá la verdad» (Díaz del Castillo, 2011, p. 351). Marina le recuerda que es mejor esperar en sus aposentos la llegada de los mensajeros que él mismo ha enviado para saber la verdad sobre lo ocurrido en Almería, antes que pedir a sus soldados un ataque contra los españoles (y por lo tanto «alborotar la ciudad»). Así las cosas, ante el reclamo del conquistador y ante este consejo dado por Marina, el emperador se dirige a Cortés comentándole una de las cuestiones esenciales que están en juego y que, considero, es uno de los asuntos de los que prescindió Cortés en su relación: «Y entonces el Montezuma dijo a Cortés: "Señor Malinche, ya que eso queréis que sea, yo tengo un hijo y dos hijas legítimos, tomaldos en rehenes, y a mí no me hagáis esta afrenta. ¿Qué dirán mis principales si me viesen llevar preso?"» (Díaz del Castillo, 2011, p. 351). A lo que responde inmediatamente el conquistador -casi que clausurando el diálogo, esto es, las «pláticas y razones»-, que fuera como fuera, tenía que ir con ellos «y no había de ser otra cosa». Lo problemático es que ante la compleja situación en la que se encuentra Moctezuma, 
está obligado a explicar a sus «principales» las razones por las que le obligan a recluirse en sus aposentos. Y lo interesante, a este respecto, es que la explicación que expondrá está influida -tal cual lo presenta Bernal Díaz- por los consejos del conquistador:

Y entonces Cortés y nuestros capitanes le hicieron muchas quiricias [le confortaron] y le dijeron que le pedían por merced que no hobiese enojo y que dijese a sus capitanes y a los de su guarda que iba de su voluntad, porque había tenido plática de su ídolo Huichilobos y de los papas que le servían que convenía para su salud y guardar su vida estar con nosotros. (Díaz del Castillo, 2011, p. 351).

A continuación, justamente cuando llegan todos los mayores principales y sus sobrinos a hablar con Moctezuma y a pedirle dichas explicaciones, el propio emperador mexicano expone casi que con las mismas palabras de Cortés -a través de la voz y la perspectiva de Bernal Díaz, cuestión que no se puede olvidar- los motivos de su reclusión:

Y el Moctezuma les respondió que él holgaba de estar algunos días allí con nosotros, de buena voluntad y no por fuerza, e que cuando él algo quisiese, que se lo diría, y que no se alborotasen ellos ni la cibdad ni tomasen pesar dello, porque aquesto que ha pasado de estar allí, que su Huichilobos lo tiene por bien, y se lo han dicho ciertos papas que lo saben, que hablaron con su ídolo sobre ello. (Díaz del Casti1lo, 2011, p. 351).

¿Cómo se puede interpretar, entonces, que Moctezuma -en el relato de Bernal Díaz- reproduzca casi que literalmente lo señalado por Cortés, esto es, que han sido tanto el dios de la guerra [Huichilobos] como los sacerdotes [papas] los que le piden a su emperador permanecer recluido? Lo más probable es que en la situación de tensión en la que se encuentran tanto los españoles como los mexicanos luego de la reclusión, y ante el riesgo de que hubiera una revuelta en la ciudad, el único que podía mantener el orden era el emperador Moctezuma, ya que solo él tenía la jerarquía y el poder suficientes para dirigirse a sus superiores, solo él podía convencerlos para que no «alborotaran» la ciudad. Según la crónica de Bernal Díaz, Cortés y los suyos dan ánimos al emperador, lo tratan con pleitesía, le piden que no se enoje por su encierro, lo introducen en sus aposentos y le ponen guardas y velas, todo ello, con el único fin de que transmita con tranquili- dad a sus superiores que él tiene el control de la situación.

Ahora, los acontecimientos que ocurrirán posteriormente, es decir, la ida de Cortés en busca de Narváez y las violaciones y asesinatos cometidos por Pedro de Alvarado en Tenochtitlán que conducirán a la «Noche Triste», harán que todo este juego de fuerzas que expone aquí Bernal Díaz - un juego en el que es obvio que Cortés gana en poder y Moctezuma pierde en jerarquía-, refleje su particular postura sobre las «pláticas y razones» que tuvieron lugar en Tenochtitlán entre el conquistador y Moctezuma. No podemos olvidar, a este respecto, que aunque comparativamente Bernal Díaz transmite mucha más información que Cortés y da más detalles de lo ocurrido en este encuentro, veremos que al igual que ocurre en la relación de Cortés, en la Historia verdadera de la conquista de la Nueva España también encontramos un «yo» que sirve de filtro para hacer referencia a la realidad.

Tampoco podemos olvidar que la personalización de la narración, es decir, la utilización que se hace del «yo» en ambos relatos fue la forma expresiva más apropiada que encontraron tanto Cortés como Bernal Díaz para dirigirse a sus destinatarios, entre otras cosas porque es justamente a través de este «yo» que ambos cronistas pueden 
reivindicar prerrogativas individuales. El género literario, finalmente, se selecciona como una respuesta a las necesidades del cronista. De acuerdo a este principio, dentro de las posibilidades expresivas asociadas al momento histórico [el descubrimiento y conquista], esto es, las crónicas, los memoriales de guerra, los exempla, las cartas, las relaciones de sucesos, etcétera, ambos cronistas seleccionan aquellos géneros que son, a su vez, testimoniales y autorreferenciales, es decir, aquellos en los que la retórica de su escritura le permite al autor ser a su vez testigo y escribano, testimonio y cronista.

Cabe preguntar, sin embargo, el motivo por el cual Cortés censuró más información que Bernal Díaz. La respuesta tiene varias instancias. Podemos pensar, en primer lugar, en el género, ya que hay diferencias importantes entre la carta de relación escrita por Cortés y la relación de sucesos o «memorial de guerra» que posteriormente Bernal Díaz convierte en una crónica que «se halla a medio camino entre la autobiografía y la historia» (Serés, 2011, p. 1161). Y justamente una de estas diferencias es que en el caso de la Historia verdadera el cro- nista selecciona una estrategia narrativa caracterizada por relatar de forma pormenorizada cada asunto del que él ha sido testigo, incluyendo «anécdotas, catálogos detallados de naves, caballos, provisiones, descripciones fisiognómicas de españoles y mexicanos, tácticas militares»y, sobre todo, «diálogos», como el que acabamos de señalar entre Cortés y Moctezuma (Serés, 2011, p. 1136). ${ }^{10}$ Así que la Historia verdadera es, en principio, una narración mucho más detallada, aunque, como hemos señalado, siga estando sometida a las filtraciones del «yo».

La segunda instancia que quisiéramos señalar tiene que ver con el propósito último de cada uno de los relatos, esto es, con la finalidad de cada narración -con eso que Segre denomina como el «contexto pragmático» de cada texto (Segre, 1985, p. 373): mientras que Cortés dirige su relación -como ya hemos señalado- a Carlos V y, por ello mismo, utiliza necesariamente una retórica jurídica en la que pretende legitimar varios de sus procedimientos, Bernal Díaz acude a una retórica marcada por un cronista cuya vida se convirtió en una constante demanda de alegatos, peticiones y probanzas de méritos y servicios, por los que exigía se le reconociesen sus gestas y curriculum de «viejo conquistador» que le permitieran conservar sus privilegios $\mathrm{y}$, obviamente, su encomienda de indios, su principal fortuna, como pretende probar con testimonios de personas «dignas de fe»: el propio Cortés y el virrey Mendoza. (Serés, 2011, pp. 1123-1124.)

Es decir, aunque en principio ambas retóricas son jurídicas, la utilizada por Bernal Díaz está mediada -y aquí retomo a Víctor Frankl [1962]- por ese particularismo e interés personal por adquirir riquezas en beneficio propio o, más específicamente, por su interés en el reparto de indios en encomienda. El propósito de Cortés, como ya se ha señalado, está más encaminado al beneficio del Rey y de la Corona.

La tercera y última instancia por señalar está relacionada con la temporalidad de la escritura, es decir, con la distancia existente entre el momento en que se escribe y los hechos

10 El profesor Serés señala, además, que una característica fundamental de la estrategia narrativa de Bernal es que su historia no sólo refleja los principales acontecimientos del descubrimiento de la conquista de México, sino también -y tal vez aquí está la diferencia respecto a la relación de Cortés- «los minúsculos detalles que le parezcan importantes para sus propósitos». Y uno de estos propósitos fue justamente el de «desmentir a Gómara y de rescatar del olvido a soldados como él, que no han tenido ningún Gómara que ensalce sus hazañas, el de legitimar la conquista como tal y, en consecuencia, su personal condición y beneficios legales de "verdadero conquistador"» (Serés, 2011, pp. 1134-1135). 
que se narran. Si miramos la carta de Cortés, podremos verificar que su escritura se ha realizado casi que en el campo de batalla, su redacción, como el mismo Cortés lo indica, se ve limitada por la actividad misma del propio conquistador. En el exordium, por ejemplo, Cortés le aclara al Rey de que a pesar de que a él le gustaría hacer referencia a absolutamente todas las «particularidades y cosas» que ha encontrado y visto en los reinos de Vuestra Alteza, esto es, en los reinos que ya ha conquistado y en aquellos que conquistará, no puede hacerlo, porque «ni mi habilidad ni la oportunidad del tiempo en que a la sazón me hallo para ello me ayudan» (Cortés, 1993, p. 161). Es decir, no puede extenderse lo suficiente tanto por las limitaciones propias de su escritura -se está alejando de algún modo de la retórica historicista característica de los cronistas oficiales-, como por la imposibilidad que tiene para dedicar tiempo a la escritura debido a sus ocupaciones militares.

Por su parte, en la Historia verdadera de Bernal Díaz, la distancia entre la escritura y los hechos es distinta, pues en su narración ya no nos encontraremos en medio del combate mientras se escribe, nos encontramos, mejor, ante una distancia temporal que le permite a Bernal, como bien lo indica Serés, seleccionar «las escenas más vívidas, las situaciones o grupos humanos plásticamente más efectivos, los diálogos más intensos o sustanciosos» (Serés, 2011, p. 1193).

Mientras que en Cortés los lectores seguimos el hilo de la narración a medida que van ocurriendo los hechos, casi que en la inmediatez, en Bernal seguimos el hilo de la narración sólo a través del recuerdo que tiene el autor sobre lo que ha ocurrido. Lo interesante es que esta diferencia temporal le permite a Bernal estructurar su relato a través de lo que el profesor Guillermo Serés ha denominado «inmediatez narrativa», es decir, por la «presencia del narrador en las acciones que relata, por el punto de vista testimonial, pero pasado por la criba de la memoria, pues no se trata de una crónica "periodística", sino de la reconstrucción de unos hechos del pasado» (Serés, 2011, p. 1193). Y es justamente esta distancia temporal la que le permite también al cronista «simultaneizar» una acción con otra, y por ello, «mostrar muchos más detalles, logra reconstruir la mayor parte de los eventos que tuvieron lugar simultáneamente o que él logra "simultaneizar" de este modo». Esta simultaneidad, como indica Serés (2011), «es una consecuencia del mismo acontecer trepidante de los hechos, del desconcierto en que se hallaban sumidos los protagonistas» (p. 1194). Por otra parte, esta técnica de la «inmediatez narrativa» utilizada por Bernal tiene otra característica esencial, el hecho de que a través de ella el lector se involucra fácilmente con lo narrado - un poco a la manera en que en las cartas de relación, por su nivel estilístico, el «yo» del relato se acerca al receptor real. El ejemplo que cita Serés para explicar esta característica es bastante ilustrativo:

Y Cortés les dijo [a los aliados indígenas] con nuestras lenguas doña Marina y Aguilar, algo enojado, que eran dinos de muerte por encomenzar la guerra; mas pues que han venido de paz, que vayan luego al otro peñol e llamen los caciques y hombres principales que en él están e trayan los muertos ... si no que habíamos de ir por ellos y ponelles cerco hasta que se mueran de sed ... Y luego fueron a los llamar ansí como se los mandó. Dejemos de hablar en ello hasta que vuelvan con la respuesta. Y digamos cómo estando platicando Cortés con el fraile Melgarejo... (Díaz del Castillo, 2011, p. 580).

Este «dejemos de hablar en ello...», le permite a Bernal cambiar de asunto y, a su vez, involucrar al lector; ya que tanto el cronista, como todos sus actuales lectores, quedamos a la espera de la respuesta. Bernal «se inmiscuye, revive de 
tal modo la acción, de forma tan inmediata, que nos hace partícipes, nos sitúa a nosotros, lectores, en su meollo» (Serés, 2011, p. 1194).

$* * *$

Expuestas estas instancias, se podría señalar que los motivos por los que un autor introduce más información que otro dependen, finalmente, de varios factores. En primer término de la intención que se puede rastrear en cada uno de los relatos señalados; en segundo término $-\mathrm{y}$ estrechamente relacionado con el anterior-, de los procedimientos retóricos utilizados por los descubridores y conquistadores, esto es, de aquellos rasgos característicos de la carta de relación y de la relación de sucesos de guerra; $y$, en último lugar, del lugar que va ocupando ese «yo» que poco a poco se va modelando a lo largo de la narración, una modelación que, como se ha indicado, está fuertemente condicionada por las cuestiones pragmáticas que subyacen a la representación del «yo» en unas relaciones de sucesos y de guerra. Las circunstancias en las que fueron producidos los relatos antes estudiados, exigían a un Cortés estructurar su narración con el objeto de cumplir con esas alegaciones de servicios o relaciones de hechos de guerra exigidos por el Rey o por la Corona. Esto significaba que el lugar del «yo» en estos textos estaba, por lo tanto, condicionado a ese receptor real al que inicialmente estaba dirigido. Es evidente, en este sentido, que al comparar ciertos episodios de esta Segunda carta de relación con los mismos episodios narrados por autores que utilizaban otra forma expresiva y respondían a otras intenciones al escribir sus testimonios -como ocurre con Bernal Díaz-, se hacen visibles los motivos por los que el conquistador de México eliminó información: Cortés no quería dejar en evidencia ante Carlos V, algunos de sus propios comportamientos. De alguna manera, quería mostrar su mejor versión, como finalmente hacemos muchos de nosotros cuando nos presentamos ante un medio social.

Lo sorprendente es que este no fue el único y más evidente caso durante el período del descubrimiento y la colona. En ciertas ocasiones, como ocurrió con la carta de relación escrita por Pedrarias de Almesto sobre la jornada de los Marañones - esa jornada en la que Lope de Aguirre extermina a buena parte de la tropa de Pedro de Ursúa, incluyéndolo a él mismo, esa jornada que universalizó ya en el siglo XX el director de cine alemán Werner Herzog con su Aguirre o la cólera de Dios (1972)-, era incluso más oportuno copiar casi que literalmente una carta escrita previamente por uno de sus amigos de jornada, Francisco Vázquez, que dejar de incluir un documento oficial [la carta de relación] para salvar su propio cuello. Inicialmente, Pedrarias de Almesto escribió una carta narrando su participación en aquella jornada, seguramente en 1562 , esto es, justo en las fechas en las que concluyeron los acontecimientos -el asesinato de Aguirre, final de toda la aventura, ocurre en octubre de 1561. Posteriormente, el propio Almesto redacta una segunda relación, seguramente en 1562 , que le serviría como documento para su declaración ante la Audiencia de Santa Fe de Bogotá realizada este mismo año. Pero lo increíble es que esta última relación responde casi que literalmente al relato escrito por el bachiller Francisco Vázquez muy seguramente en 1561 o, como mucho, un año después. Incluso en la edición preparada por Feliciano Ramírez de Arellano para la Colección de Bibliófilos Españoles en 1881, el editor aclara que el autor de la relación es el bachiller Francisco Vázquez, pues fue él quien escribió «el trabajo primitivo y original» y que, posteriormente, "se hicieron en él todas aquellas alteraciones que más podían convenir á los fines del que pretende aparecer como autor», esto es, Pedrarias de Almesto (Ramírez de Arellano, 1881, p. XIII). El Marqués de la Fuensanta del Valle (Ramírez de Arellano) dedica la segunda sección de su «Advertencia» a demostrar que fue Vázquez, en 
efecto, el autor de la relación, y que lo que hace Almesto es «apropiarse» de un material, cosa que al propio Marqués le parece «difícil, por no decir imposible», sobre todo porque considera algo contradictorio que un autor se apropie de «obras ajenas á fuerza de astucia, de supresiones hábiles, de asertos cuidadosamente preparados, de previsoras enmiendas y de calculadas interpolaciones» (Ramírez de Arellano, 1881, pp. XXVIII-XXIX). Para el Marqués, el relato de Almesto no es otra cosa que un intento constante de este soldado por intentar pasarse como el verdadero autor de la relación sobre la jornada. El juicio que hace en esta sección sobre el proceder de Almesto es contundente. «En efecto», dice,

cuando en los trabajos intelectuales se siguen las huellas de otro, sucede que la labor ya dada y las frases ya hechas del autor que sirve de modelo, ejercen un influjo poderoso é inevitable sobre el que imita, el cual se afana por aprovechar á todo trance el mayor número posible de pensamientos y párrafos, de suerte, que es necesario tener un talento muy superior y estar además muy sobre sí para lograr sustraerse á los efectos de esta fascinación irresistible; y hé aquí la explicación del enorme descuido de Pedrárias, que invenciblemente arrastrado por el giro y el corte de la narración del Bachiller, siguió su impulso y aprovechó sus conceptos, sin sospechar que él mismo se desmentía y se denunciaba. (Ramírez de Arellano, 1881, p. XXX).

Lo más relevante, para nuestros intereses, es que en la copia que hace Almesto del relato del bachiller Vázquez, el propio soldado-cronista incluye su individualidad, introduce su propio «yo» cuando más le parece oportuno, imponiéndolo al «yo» del propio Vázquez. Que sirva de ejemplo el episodio en el que el propio Aguirre acaba de asesinar a su propia hija (motivo por el cual finalmente él mismo es asesinado), episodio en el que, según la versión del propio Almesto - a diferencia de lo que ocurre en el relato de Vázquez, en el que no aparece la figura de Pedrarias de Almesto- es este último el principal protagonista:

el Diego García de Paredes, Maese de campo de $\mathrm{Su}$ Majestad, mandó apear á uno de los que allí venían en su compañía, y le dio el caballo al dicho Pedrarias, $\mathrm{y}$ le dijo que fuesen ambos delante, y los demás tras él, que serian como hasta quince hombres de á caballo; y fueron de una arremetida al fuerte, y el Mae- se de campo y el Pedrarias entraron dentro, no con poco temor de la artillería, que pudiera estar el tirano con ella para dispararla en ellos; y fué Dios servido que, como entraron, no habia el tirano caído en ello, con su turbacion; y allí se apearon, y rindieron el tirano; el cual, como vido que el Maese de campo y el Pedrarias echaron mano, y le amagaban á dar con una espada, dijo: «iAh, señor Pedrarias! ¿qué malas obras os he hecho yo? $\mathrm{Y}$ el Pedrarias le comenzó á querer desarmar, y le quitó un capote pardo con pasamanos que tenia sobre las armas y luego el Diego García de Paredes le quitó el coselete; y luego llegó toda la gente de golpe, y allí hallaron á los piés del tirano á su hija muerta á puñaladas. (Almesto, 1881, pp. 182-183).

Es evidente que, comparativamente con la versión dada por su fuente, Almesto tiene un concreto interés en que él mismo aparezca como principal protagonista del posterior asesinato del tirano, así él no haya sido el autor material. ¿Pedrarias de Almesto no estaba pensando, en últimas, en esa versión que de sí mismo estaba dando ante una futura autoridad, aquella que tendría que enfrentar en la Audiencia de Santa Fe de Bogotá en 1562? Es 
claro que, en la copia que hace Almesto del relato de Vázquez, él mismo incluye su «yo», su individualidad, siempre en beneficio propio, como ocurre con los casos de Cortés o de Bernal Díaz antes señalados. Así que, el hecho de incluir o dejar de lado cierta información no era una cuestión secundaria, pues al hacerlo se estaba perfilando un «yo» ante el receptor real. La información que se daba era una cuestión de primer orden, porque al final lo que estaba en juego no era otra cosa que su propio «yo», su propio «yo» ante una autoridad, incluso ante Dios. Y esto no era poca cosa.

\section{Referencias}

Albuquerque García, L. (2008). Apuntes sobre crónicas de Indias y relatos de viajes. Letras, (57-58), 11-23.

Almesto, P. (1881). Relación de todo lo que sucedió en la jornada de Omagua y Dorado hecha por el Gobernador Pedro de Orsúa, «advertencia preliminar» de Feliciano Ramírez de Arellano, Marqués de la Fuensanta del Valle, Sociedad de Bibliófilos Españoles, n. 130, Madrid.

Almesto, P. (2012). Relación de la jornada de Omagua y El Dorado, estudio, edición y notas de Álvaro Baraibar, incluye un facsímil del manuscrito. New York: IDEA/IGAS.

Cervantes de Salazar, F. (1971). Crónica de la Nueva España, edición de Manuel Magallón; estudio preliminar e indices de Agustín Millares Carlo (). Madrid: Ediciones Atlas.

Cortés, H. (1993). Cartas de relación, edición de Ángel Delgado Gómez. Madrid: Clásicos Castalia.

Delgado Gómez, Á. (1993). Introducción biográfica y critica de su edición de Hernán Cortés, Cartas de relación (pp. 9-102). Madrid: Clásicos Castalia.

Díaz del Castillo, B. (2011). Historia verdadera de la conquista de la Nueva España, edición, estudio y notas de Guillermo Serés. Madrid: Real Academia Española.

Frankl, V. (1962). Hernán Cortés y la tradición de las siete partidas. Revista de Historia de América, (53-54), 9-74.

González Otero, A. (2016). Definiciones y aproximaciones teóricas al género de la literatura de viajes. La Palabra, (29), 65-78.

Greenblatt, S. (2005). Renaissance Self-Fashioning. From More to Shakespeare, with a new Preface. Chicago \& London: The University of Chicago Press.

Guillén, C. (1998). Múltiples moradas. Ensayo de literatura comparada. Barcelona: Tusquets. 
Merrim, S. (1986). Ariadnes's thread: auto-bio-graphy, history, and Cortés Segunda Carta-Relación. Dispositio, 11(28-29), 57-83.

Mignolo, W. (1992). Cartas, crónicas y relaciones, en Historia de la Literatura Hispanoamericana (tomo I). En: L. Íñigo Madrigal (coord.), Época colonial (pp. 57-116). Madrid: Cátedra.

Molloy, S. (2001). Acto de presencia. La escritura autobiográfica en Hispanoamérica. México: El Colegio de México, Fondo de Cultura Económica.

Pastor, B., \& Callau, S. (2011). Lope de Aguirre y la rebelión de los marañones. Madrid: Castalia.

Ramírez de Arellano, F. (1881). Advertencia preliminar a su edición de Almesto, Pedrarias de, Relación de todo lo que sucedió en la jornada de Omgaua y Dorado hecha por el Gobernador Pedro de Orsúa, Sociedad de Bibliófilos Españoles, (130), Madrid, pp. V-XLVII.

Segre, C. (1985). Principios de análisis del texto literario, editorial Crítica, Barcelona.

Serés, G. (2011). Estudios y anexos de Bernal Díaz del Castillo, Historia verdadera de la conquista de la Nueva España, Edición, estudio y notas de Guillermo Serés (pp. 1117-1457). Madrid: Real Academia Española.Vázquez, F. (1881). Relación de todo lo que sucedió en la jornada de Omagua y Dorado hecha por el Gobernador Pedro de Orsúa, «Advertencia preliminar» de Feliciano Ramírez de Arellano, Marqués de la Fuensanta del Valle, Sociedad de Bibliófilos Españoles, (130), Madrid. 